Fecha de recepción: noviembre 2019 Fecha de aceptación: diciembre 2019 Versión final: marzo 2020

\section{La relación de la enseñanza del diseño entre el producto impreso y la selección del sistema de impresión y acabados adecuados}

Pablo Guzmán Paredes ${ }^{(1)}$

\begin{abstract}
Resumen: Dentro de la enseñanza del diseño es necesario comprender que la configuración de un producto comprende la conceptualización y la relación de cada uno de los pasos que se deben seguir para llegar a obtener un producto impreso, esto nos lleva a tomar en cuenta desde el inicio del proceso a la adecuada selección del sistema de impresión y post prensa, los cuales deben ir acorde con el concepto inicial del producto comunicacional. Adicionalmente, las exigencias actuales relacionadas con normas medioambientales adquieren principal interés en la configuración de productos gráficos, para esto es imprescindible que desde la academia se forme a los nuevos diseñadores con todas las herramientas para que sean capaces de enfrentar los nuevos retos que la profesión presenta en la relación Diseño Gráfico - producto impreso - medioambiente, tomando en cuenta que tanto el sistema de impresión como los acabados utilizados deben ser seleccionados desde el inicio del proceso como parte del concepto que se desea comunicar.
\end{abstract}

Palabras clave: Diseño gráfico - procesos de impresión - acabados - enseñanza medioambiente - innovación

[Resúmenes en inglés y portugués en la página 232]

(1) Adscrito a la Pontificia Universidad Católica del Ecuador, en la Carrera de Diseño Gráfico de la Facultad de Arquitectura, Diseño y Artes. Diseñador y Magíster en Administración de Empresas. Docente PUCE.

\title{
Desarrollo
}

"La práctica del diseño presupone también conocimiento de tecnologías de producción”. (Frascara, 2017, p. 22)

Una parte muy importante el proceso de diseño es la configuración de prototipos y su posterior producción en serie, por este motivo es de suma relevancia que los diseñadores gráficos en formación conozcan, entiendan y apliquen los diferentes sistemas de impresión 
existentes dentro de la industria nacional e internacional, esto se debe presentar a partir de la comprensión de los procesos que se encuentran vinculados en el ámbito de la impresión seriada, es decir que iniciando por la pre prensa, pasando por la impresión como tal hasta llegar a la adecuada selección de acabados, ya sean los tradicionales o las nuevas técnicas que se han dado a conocer en los últimos años, que brindarán un valor agregado al producto impreso final, teniendo siempre presente el constante avance de la tecnología, esto permite que en la actualidad se presenten innovadoras maneras de otorgarle dicho valor a los productos impresos para que estos se conviertan en verdaderas piezas comunicacionales y no en simples hojas impresas que posteriormente serán desechadas sin cumplir su objetivo principal, de esta manera se parte con la premisa planteada por Frascara (2017) que indica que los nuevos diseñadores deben ser formados para la realidad y en la realidad, se propone entonces una enseñanza del diseño gráfico vinculada con la industria, el desarrollo tecnológico y de la mano de la conciencia del impacto ecológico que se provoca con cada acción realizada.

Asimismo, Tobón (2010) explica que al proponer la metodología de trabajo en proyectos se incentiva a los estudiantes a no únicamente trabajar en la resolución de problemas, sino que se busca que ellos entiendan todo el contexto relacionado con el problema y vayan más allá de la información para que, en primer lugar, desarrollen una actividad cognitiva y tengan contacto con la realidad parar asumir una postura frente al problema (Tobón, 2010, p.17) Gatter (2010) indica que dada su experiencia en el campo de la impresión puede señalar que los diseñadores cometen constantes errores en la elaboración de artes finales los cuales son enviados a los impresores en un estado que no es aceptable, lo que provoca retrasos en los tiempos de trabajo debido a que es necesario emplearlo en corregir los mencionados errores:

Los principales aspectos que generan problemas son la ganancia de punto, calibración de imágenes, reventado (trapping), el mantener imágenes con perfil RGB y no cambiarlas a CMYK, y crear archivos en formato PDF que no contenga errores $(2010$, p. 7$)$.

La enseñanza de los diferentes procesos de impresión y acabados para futuros diseñadores no pretende que los estudiantes lleguen a convertirse en expertos impresores o que dominen todos y cada uno de los diversos aspectos, más que nada técnicos, que intervienen en cada uno de los sistemas de impresión vigentes dentro de la industria gráfica ecuatoriana, al contrario, desde la cátedra de Producción gráfica de impresos en la carrera de Diseño Gráfico de la Pontificia Universidad Católica del Ecuador se busca que los estudiantes estén en capacidad de armar artes finales u originales sin errores técnicos que interrumpan el correcto y normal flujo de trabajo del proceso de impresión pero principalmente se pretende guiar a los estudiantes para que a partir de la concepción de la pieza gráfica, que posteriormente será impresa, y todo relacionado con el trabajo de diseño.

Se busca que incurran en la experimentación con diferentes y versátiles procesos, sustratos y tipos de acabados que brinda la industria actualmente, muchos de ellos relacionados con el avance vertiginoso que ha tenido la impresión digital en los últimos 30 años 
y especialmente en el último lustro en el que en el mercado ecuatoriano han ingresado diferentes equipos de impresión y de acabados que antes eran exclusividad del sistema de impresión offset y que ahora pueden ser aplicados a productos impresos en láser, prensa digital o sistema HP Indigo (https://www8.hp.com/), con lo cual se logra una evidente mejora en la calidad final de los productos impresos. Asimismo, el desarrollo de la tecnología de prensas digitales, en todas sus variantes, ha permitido a la impresión digital competir hombro a hombro, y en algunos casos desplazar, con sistemas como la impresión offset y la flexografía, actualmente en la ciudad de Quito existen centros de impresión que ofrecen esta tecnología, con lo cual se pueden producir impresos de alta calidad a costos razonables y en muchos casos ofertando el servicio al público en general para producción de tirajes bajos. Estos hechos se los pudieron evidenciar durante la realización de la feria FIGRAMPA de la industria gráfica llevada a cabo en Quito - Ecuador entre los días 7 y 10 de noviembre de 2019. Se debe tener muy claro el concepto de tecnología, puesto que esta es muy importante como herramienta para ayudar en el trabajo del diseñador, pero jamás llegará a sustituirlo (https://graffica.info).

Es entonces imprescindible entender la importancia de conocer las particularidades de los principales procesos de impresión y de acabados en la formación de nuevos diseñadores gráficos, más allá de la tendencia notoria de las nuevas generaciones hacia el desarrollo de productos digitales, la práctica nos enseña que una vez obtenido el título y en sus primeros intentos de insertarse en el mercado laboral, hasta encontrar el camino hacia una especialización, ya sea esta laboral o académica, se tornará necesario ejecutar diferentes tipos de proyectos y entre esos se encuentra la producción de impresos, razón por la cual es necesario fortalecer desde la academia el conocimiento de las tecnologías relacionadas con la impresión y el desarrollo de las mismas. También es importante indicar que la tendencia de trabajos de titulación de los estudiantes es cíclica, de esta manera, en el presente año la mayoría de estudiantes titulados en la Carrera de Diseño de la PUCE han obtenido su título de pregrado con proyectos relacionados a la producción gráfica de impresos, la realidad en años anteriores muestra que la tendencia iba hacia proyectos netamente digitales (Repositorio PUCE, 2019).

Para citar un ejemplo, en el año 2019 se planteó un proyecto de titulación de la estudiante Jennifer Vega Carrera, como se lo muestra en la Figura 1, la estudiante plantea un proyecto enfocado a ser una ayuda para el tratamiento de pacientes con la enfermedad de Alzheimer en etapas leve y moderada, partiendo del concepto del Aprendizaje basado en problemas donde los estudiantes incorporan en el proceso de aprendizaje factores sociales (Escribano y Del Valle, 2010. p. 20), este proyecto está constituido por aproximadamente 250 actividades relacionadas con la terapia cognitiva de los pacientes, el mencionado proyecto desde su concepción parte con la idea de proponer únicamente productos impresos, el desarrollo de cada uno de los elementos fue de la mano de la propuesta gráfica que la estudiante desarrolló. Se trabajó cada una de las piezas para que estas reflejen el concepto planteado por la estudiante. Es decir que la se planteó el producto como un sistema complejo en el que cada elemento es parte de un todo, incluyendo el proceso de fabricación del producto (Mazzeo, 2017). 


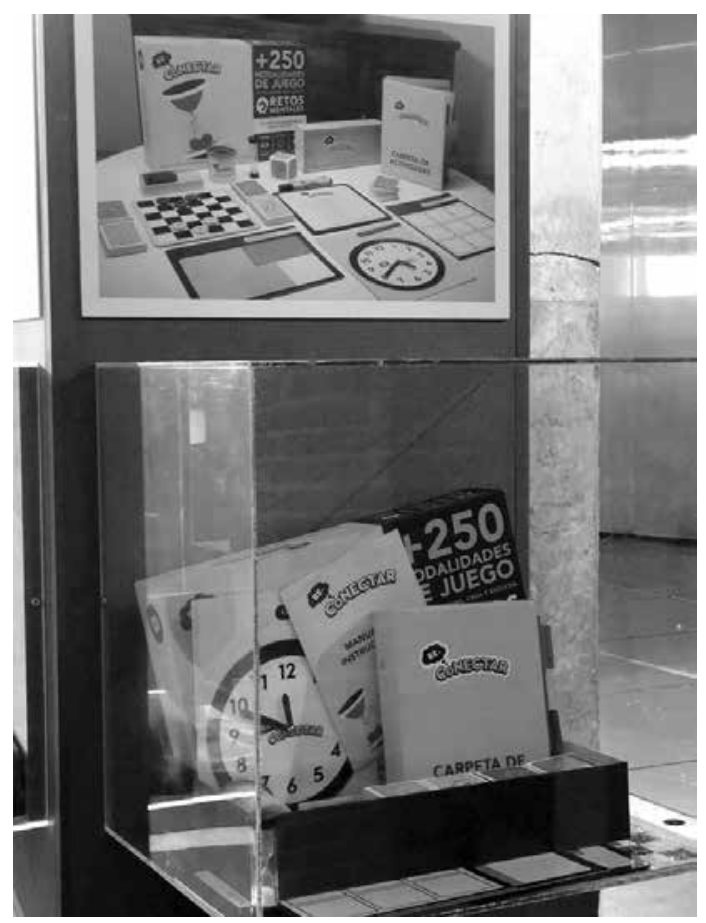

Figura 1. Proyecto de titulación, año 2019, con objetos impresos. Fuente: Jennifer Vega, Alumni PUCE.

Desde el inicio del proyecto, la estudiante planteó la necesidad de desarrollar cada una de las piezas gráficas contemplando todas las posibilidades que los diversos sistemas de impresión, sustratos y acabados, existentes en el medio, podían aportar al producto el valor agregado que el proyecto requería.

Se experimentó con diversos sustratos para la elaboración de sobres, tarjetas, empaques internos, y otros tipos de piezas que el proyecto incluía, se realizaron diversas pruebas de impresión en diversos sustratos para definir los más adecuados según el uso que cada uno de los elementos tendría por el usuario del producto; pero la mayor experimentación se realizó en el diseño del empaque principal del producto, la estudiante planteó la configuración gráfica de acuerdo al sistema de impresión en el que iba a elaborar, para así favorecer el proceso de comunicación. De esta manera se realizaron prototipos en dos procesos diferentes con diversos tipos de sustratos que permitieron finalmente tomar la elección más adecuada acorde con la usabilidad del producto. Se realizaron pruebas con sistemas de impresión en gran formato, estas pruebas permitieron visibilizar el conjunto 
del producto finalizado y la utilidad que prestaba el sustrato para el uso del producto, de igual manera expusieron las posibles fallas que los materiales podrían tener durante la vida útil del producto, se experimentó con sistema de impresión en cama plana y cartón microcorrugado, pruebas que no llenaron las expectativas de uso debido a que los pliegues del empaque presentaban un rápido desgaste, por lo que fue eliminada la opción, finalmente se realizó un prototipo con impresión en gran formato sobre vinil adhesivo, lo que permitió colocar el impreso sobre cualquier tipo de cartón resistente y que permita realizar pliegues sin desgastarse rápidamente, de esta manera se obtuvieron los resultados deseados y se continuó con el proceso de diseño acorde con el concepto planteado y se llegó a la consecución de un producto complejo pero muy bien logrado que le permitió a su autora ser seleccionada entre los " 50 talentos. Ideas para un mundo mejor" de la pasada Bienal Iberoamericana de Diseño llevada a cabo en la ciudad de Madrid a partir del 20 de noviembre del año 2019 (http://bid-dimad.org/).

Dada la experiencia obtenida en el mencionado proyecto entre el proceso de diseño y la producción de un objeto que finalmente fue validado con el usuario y cumplió con los parámetros de usabilidad estipulados, se realizó el planteamiento del desarrollo de la nueva asignatura de Producción gráfica de impresos, la cual va de la mano con la implementación de la nueva malla curricular en la carrera de Diseño Gráfico de la PUCE, asignatura en la que se aporta con el conocimiento de materiales y soportes para impresión, los diferentes procesos de impresión seriada y acabados para la reproducción de las artes gráficas, su principal propósito es el de identificar las características de los medios de producción y de los materiales para optimizar procesos, costos, uso y optimización de sustratos, reforzando así la importancia de, según Yeang (2006), minimizar el impacto de la huella ecológica, partiendo de la premisa que el diseño debe ser además de social y ética también ecológicamente responsable. Adicionalmente, dentro de la asignatura, se refuerza el hecho de elaborar artes finales sin errores para evitar problemas con proveedores de los diferentes servicios relacionados con impresión y clientes dentro de la práctica profesional. $\mathrm{Al}$ finalizar el curso, los estudiantes deberán estar en capacidad de reconocer, diferenciar y hacer uso de los diversos tipos de tecnología presente en la industria gráfica ecuatoriana y definir qué procesos de impresión y acabados serán los adecuados dependiendo el proyecto de diseño en el que estén trabajando para que el producto final sea un verdadero aporte (Rediseño Carrera de Diseño Gráfico PUCE, 2016).

De esta manera, la enseñanza de los diferentes procesos de producción de impresos en la nueva malla curricular condensa la información que anteriormente se impartía en diferentes módulos en un solo periodo semestral, la cual arranca con un acercamiento a la historia de la impresión, generalidades datos técnicos y particularidades, posteriormente se realiza una exploración a los diferentes sustratos útiles para impresión, para lo cual se ha elaborado una división académica en materiales convencionales y no convencionales, los estudiantes tienen un acercamiento a los diferentes sustratos al elaborar un catálogo donde deben realizar una recolección de diferentes materiales y los catalogan de acuerdo a la división académica antes mencionada, adicionalmente investigan el para qué proceso de impresión es útil cada uno de los materiales que presentan en su catálogo, así ellos pueden empezar a identificar los diferentes sustratos que existen en el mercado, ver las 
probabilidades de aplicación de diversos tipos de impresión de acuerdo al material y todas las opciones que existen para elaborar productos gráficos impresos, para la elaboración de estos materiales es necesario que los estudiantes investiguen sobre los diferentes tipos de materiales existentes en el mercado, visiten distribuidores de papel y se organicen para obtener la mayor cantidad de materiales para alimentar su catálogo, otro de los objetivos de este ejercicio es que ellos puedan tener una fuente de información permanente para la ejecución de futuros trabajos impresos que deberá ser útil tanto para su carrera universitaria como para su vida laboral.

Posteriormente, se continúa con el desarrollo de la teoría sobre materiales con el estudio del papel, su producción y reciclaje, además de conocer los conceptos de fibra, gramaje, calibre, pliego, formato, carteo, entre otros. En este punto se empieza a trabajar con el concepto de desperdicio, puesto que se pretende inculcar en los estudiantes la filosofía de la denominada producción ajustada (Cuatrecasas, 2012, p. 110), enfocada al uso minimizado de recursos, para lo cual también se realiza una división académica que explica sobre el desperdicio técnico y el desperdicio real, los estudiantes están en capacidad de calcular la cantidad de sustrato necesaria para cada proyecto, proponer el formato de impresión más adecuado para minimizar el desperdicio y de esta manera tener presente el concepto de ser ecológicamente responsables. Para reforzar el tema ecológico los estudiantes realizan una investigación sobre certificaciones ambientales o ecoetiquetas, que son sellos o marcas que diferentes organizaciones otorgan a productos que durante su ciclo de vida disminuyen el impacto ambiental en relación a productos similares (Capuz Rizo, 2002, p. 189), tanto a nivel nacional como internacional, esta investigación se torna importante puesto que abre el abanico de posibilidades de trabajar con sustratos que han obtenido algún tipo de certificación, enfatizando el tema de minimizar la huella de carbono y basados en datos reales, como por ejemplo los de la Asociación Española de fabricantes de envases y embalajes de cartón ondulado (AFCO) quienes indican que en los últimos 3 años los productores de este tipo de cartón han reducido en un 11,7 \% la huella que deja la fabricación de su producto (www.afco.es), asimismo, la organización Cluster de Papel del País Vasco (www.clusterpapel.com) indica que para el año 2010 ya habían reducido en un 13, $95 \%$ su huella de carbono.

Previo al estudio individual de cada uno de los sistemas de impresión se dan a conocer conceptos generales en el armado de artes, como son los siguientes:

- Gestión de color,

- Normas ISO 12647,

- Ganancia de punto,

- Sobreimpresión, reserva, traslape, registro y bandas de color,

- Resolución de las imágenes, y

- Formatos de imágenes adecuados para impresión.

El siguiente paso es conocer sobre los diferentes sub procesos dentro de los diversos sistemas de impresión, la pre prensa, la prensa y la post prensa, se realiza una revisión general para después profundizar en cada uno de los diferentes sistemas de impresión que serán revisados, los cuales son: 
- Impresión digital, la cual comprende impresión de pequeño formato (láser e inyección a tinta), impresión de gran formato (gigantografías) y prensa digital con todos los avances que ha tenido en los últimos años,

- Impresión offset,

- Impresión flexográfica,

- Impresión serigráfica, e

- Impresión tampográfica.

Cada uno de los sistemas de impresión es estudiado particularmente y se aborda desde el armado del arte, analizando cada una de las especificaciones que cada proceso tiene, en los procesos en los que se utilizan fotografías se recalca a los estudiantes la transformación del perfil de color a CMYK, que como se lo había indicado anteriormente, es uno de los principales problemas con los que se encuentran los impresores al momento de recibir artes finales y es un error constante entre los estudiantes; se profundiza en el tratamiento adecuado de las imágenes, especialmente relacionadas con la resolución, esto debido a que la experiencia laboral indica que no se le presta la atención debida a este particular y se continúan cometiendo errores al enviar los archivos para impresión, lo que provoca al final cambios en tonalidades que pueden presentar problemas con clientes.

Uno de los aspectos técnicos que los estudiantes deben conocer y entender es el proceso de rasterización de la imagen, básicamente se busca que logren comprender que los documentos son traducidos de un lenguaje binario al lenguaje PostScript para que tanto equipos generadores de placas térmicas, fotolitos o impresoras realicen la acción deseada, de esta manera se explica de una forma sencilla un proceso que en algunos casos presenta errores al momento de imprimir y del que generalmente no se conoce el porqué, pero los estudiantes pueden llegar a comprender que tanto imágenes como fuentes tipográficas pueden presentar errores que impidan que el documento se imprima adecuadamente (https://www.adobe.com)

Dentro del estudio de cada uno de los diferentes sistemas se realizan ejercicios de aplicación de los mismos, intentando concatenar estas prácticas con el desarrollo de la materia principal del nivel, Taller de Diseño, puesto que la carrera impulsa la enseñanza del diseño basada en problemas abordados como proyectos y se pretende que los estudiantes contemplen todos los aspectos envueltos en la práctica del diseño, incluyendo clientes y usuarios (Frascara, 2017, p.51), de esta manera se ponen en práctica los conceptos impartidos en clase con un proyecto práctico que posteriormente será evaluado por todos los docentes del nivel, adicionalmente, dentro de la cátedra se realizan micro proyectos para que los estudiantes puedan evidenciar cada uno de los temas revisados y ponerlos en práctica. De esta manera se refuerza el conocimiento adquirido y los estudiantes poco a poco desarrollan el hábito de elaborar artes finales sin errores técnicos.

De esta manera se inicia con el estudio de cada uno de los sistemas, partiendo, como se lo ha mencionado, con aspectos técnicos de cada uno de los diversos sistemas para proceder con ejercicios prácticos de armado de artes finales para cada uno de los procesos de impresión, debido a la relación de las diferentes asignaturas dentro del nivel de estudio, se requiere que el primer sistema estudiado sea la impresión digital y especialmente el gran formato, los estudiantes comprenden la importancia de trabajar con imágenes y a la reso- 
lución adecuada para evitar contratiempos en el proceso de impresión como tal. Se inicia con la revisión del proceso de impresión en gran formato, los estudiantes preparan los elementos para elaborar una pieza gráfica cuyo concepto y maquetación serán desarrollados en la asignatura de Taller de diseño con el soporte de las otras asignaturas del nivel, de esta manera los estudiantes comprueban que los detalles técnicos del armado del arte se reflejan en el producto impreso final. Posteriormente se revisa el proceso de impresión digital en pequeño formato, de esta manera entre un sistema y otro los estudiantes empiezan a diferenciar el uso adecuado de la resolución de la imagen de acuerdo al sistema empleado puesto que entre gran y pequeño formato el manejo de la resolución es diferente, dadas las características de uso del producto impreso. Se ejecutan diferentes piezas gráficas donde al mismo tiempo se plantean la aplicación de procesos de acabados gráficos, no únicamente los tradicionales sino también las nuevas aplicaciones que existen en el medio como pueden ser foil para impresión láser o serigrafía.

Otro ejercicio que se realiza es el de aplicación de la sublimación, técnica que se encuentra en boga en el medio y que les permite a los estudiantes acceder productos diferentes a los productos impresos tradicionales, como ejercicio de aplicación se propone elaborar una historia contada por escenas, cada escena será representada en un producto sublimado, siendo uno de los resultados de aprendizaje de la asignatura el de trabajo en equipo, se permite que el curso se organice y de esta manera se arranca con la división de escenas, cada estudiante tendrá que bocetar una escena, dada la calidad de los bocetos se nombran ilustradores que serán los encargados de ilustrar todas las escenas previamente bocetadas, otro grupo se encarga de armar las escenografías de las escenas, otro del decorado, el siguiente grupo se encarga de la producción y finalmente otro grupo deberá hacer el levantamiento fotográfico como evidencia del ejercicio.

El siguiente proceso que se estudia es el sistema de impresión offset, se presenta una explicación del funcionamiento del sistema, principalmente enfocada hacia aspectos técnicos relacionados con el armado de artes, sus principales diferencias con la impresión digital, ventajas y desventajas, el funcionamiento de la tecnología Computer tu film (Gatter, 2010, p. 17), se conoce la conformación de los medios tonos mediante el tramado; para que los estudiantes logren comprender cómo funciona la separación de colores y las pruebas de color que se realizan basadas en fotolito, previas a la elaboración de placas térmicas, se realiza un ejercicio en el que se prepara un arte sencillo y mediante el uso de software, se crea la separación de colores para después imprimirla en cuatro diferentes acetatos, o en los necesarios si es que los estudiantes hacen uso de tintas planas, este ejercicio es sumamente didáctico puesto que es una manera simple de entender cómo se conforman los impresos al descomponerse en los diferentes colores de impresión de los artes finales en el momento de elaborar la separación de colores previo a la impresión, asimismo, comprenden cómo termina conformándose un impreso con la evidencia plasmada en acetatos a manera de prueba de color. Posteriormente se explica el sistema Computer to plate (Gatter, 2010, p. 19), para que los estudiantes conozcan las principales diferencias entre los dos sistemas, tomando en cuenta en que "CTP" es el sistema más utilizado en la industria por la disminución de costos, los estudiantes reconocen la diferencia entre una malla de medios tonos, propia de la elaboración de películas, y la malla estocástica, propia del sistema de 
elaboración directa de placas. Basados en sus propuestas de acabados gráficos se analiza cada uno de ellas para que los estudiantes puedan entender el porqué es posible o no aplicarlos y comprendan la necesidad de pensar en el uso final que se dará a la pieza gráfica relacionada con los diferentes procesos de producción.

El siguiente sistema estudiado es la impresión flexográfica, siguiendo con la metodología planteada, se presentan generalidades de los aspectos técnicos del sistema de impresión y se procede a realizar una aplicación práctica, en este proceso los estudiantes deben conocer uno de las principales particularidades que la flexografía presenta y es la importancia de la deformación del arte para que se adapte a las formas curvas de los envases en el momento de aplicar sustrato impreso a la superficie en la que será expuesto, se plantea un ejercicio práctico en el que se debe realizar una etiqueta para cualquier tipo de envase y se requiere que cada estudiante realice una investigación de cómo se debe deformar la etiqueta para que esta se adapte a las formas del envase y así la lectura de la imagen sea adecuada, en un proceso de prueba y error los estudiantes presentan sus propuestas de etiquetas aplicando deformación y de esta manera entienden el funcionamiento del proceso. Es parte importante de la asignatura incentivar a que los estudiantes investiguen sobre diversos procesos que se realizan para complementar la producción de impresos, por este motivo se les solicita investigar individualmente para que adquieran conocimientos como parte del trabajo autónomo.

Para la impresión serigráfica se realiza la explicación respectiva del sistema y para el ejercicio práctico se propone a los estudiantes generar una imagen con tintas planas, para poder elaborar la respectiva separación de color, esta imagen será aplicada sobre una plegadiza, para lo cual también deben preparar el plano de troquel del producto, posteriormente se procede a la elaboración de la separación de colores según cada arte, se realiza la impresión de los positivos de cada color en acetatos para continuar con la preparación de las respectivas mallas, como en algunos casos se presenta la dificultad de acceder a un laboratorio de serigrafía para proceder con la emulsión y revelado de las mallas se presenta la posibilidad de trabajar con otro proceso novedoso para evitar emulsionar las mallas y es el de elaborar los negativos con vinil y plotter de corte, de esta manera los estudiantes deben preparar los artes para cortar en el vinil y armar las mallas necesarias, de esta manera también se aprovecha el ejercicio para que los estudiantes tengan el acercamiento necesario con la técnica de plotter de corte y aprendan a transferir el vinil desde el papel encerado hacia el sustrato en donde debe ser adherido, una de las dificultades de este ejercicio es que cada uno de los estudiantes gestione particularmente cada una de las actividades, es decir que fuera del aula de clase ellos deben organizarse para conseguir las mallas, las tintas, investigar sobre el proceso de serigrafía y así presentar el producto terminado. Esto se procura realizar para que los estudiantes empiecen a gestionar las diferentes actividades que son necesarias ejecutar para elaborar un producto impreso, de todas maneras este proceso presenta ciertas complicaciones dado que los estudiantes no están acostumbrados a manejar ciertas actividades y usualmente esperan que los docentes las gestionen por ellos, hecho que en la vida profesional no se presenta y es necesario enfrentarlos a diferentes tipos de complicaciones para que puedan superarlas. 
Finalmente se estudia el sistema de tampografía, se explica el funcionamiento técnico y se procede a realizar el ejercicio práctico que consiste en elaborar una marca y realizar la separación de color respectiva, dado que este sistema es el que más complicaciones presenta en el momento de realizar una muestra, puesto que los proveedores de este tipo de impresión no realizan productos de manera unitaria, es necesario utilizar otro tipo de herramientas para mostrar la aplicación del arte en el producto final, para esto se solicita una imagen render de un producto en la que los estudiantes presentan una representación del producto con la respectiva aplicación, adicionalmente que deben presentar la respectiva separación de colores correctamente elaborada, es decir que la nomenclatura sea adecuada y que se utilice marcas de registro.

Con la ejecución de ejercicios prácticos se pretende que los estudiantes tengan un acercamiento real al trabajo de elaboración de artes y trabajo con proveedores, siendo este punto un aspecto muy importante dentro de su preparación, para que puedan escoger las mejores opciones que el mercado presenta; es por esto que dentro de cada proceso de impresión se plantean ejercicios prácticos para que los estudiantes elaboren artes de acuerdo a las explicaciones teóricas impartidas en clase y a los requerimientos de cada sistema de impresión, así ellos cada vez más van adquiriendo destrezas para elaborar artes sin errores, minimizando el desperdicio y seleccionando con anticipación sustratos, sistemas de impresión y acabados, de esta manera se enfrentan a la oferta del mercado y buscan las mejores opciones para hacer la entrega de productos de calidad.

Es necesario indicar que en todos los casos de ejercicios prácticos se evalúa por medio de rúbrica que plantea claramente los componentes de evaluación, estos son:

- Adecuado perfil de color del documento,

- Adecuado perfil de color de las imágenes,

- Adecuada resolución de las imágenes de acuerdo al sistema de impresión,

- Adecuado formato de las imágenes,

- Uso de registros y sangrado,

- Uso de traslapes y reservas,

- Nomenclatura adecuada para acabados,

- Uso adecuado de colores planos, y

- Calidad del producto impreso

Básicamente con esos parámetros se mide el cumplimiento técnico de las necesidades de un arte final para impresión, esta rúbrica pretende más que evaluar, hacer caer en cuenta a los estudiantes qué parámetros deben cumplir para lograr obtener productos impresos de calidad que aporten al diseño y que con anticipación corrijan los errores que puedan tener y los eviten antes de enviar la pieza gráfica para su evaluación, así van generando una cultura de revisión de sus archivos antes de enviarlos al impresor. Este proceso también presenta sus inconvenientes dado que no hay una costumbre marcada en los estudiantes de revisar su aula virtual antes de enviar sus trabajos, se quedan con lo explicado en clase y donde su memoria o apuntes les puede traicionar, por lo que se realiza especial énfasis en solicitar que revisen los parámetros de evaluación antes de enviar sus trabajos, haciéndoles notar que si un impresor recibe sus documentos con errores o los puede rechazar y no 
imprimirlos, siendo este el menor de los problemas, o imprimirlos con dichos errores, lo que tendría diferentes tipos de consecuencias no positivas hacia el diseñador empezando por la pérdida de tiempo hasta llegar a pérdidas económicas.

\section{La importancia de la visita técnica}

Desde la escuela se ha hecho especial énfasis en el acercamiento de los estudiantes a la realidad de la industria, por este motivo se proponen diferentes visitas técnicas guiadas por el mismo personal de las diversas empresas relacionadas con las artes gráficas, de esta manera los estudiantes pueden palpar los diferentes procesos de producción de piezas gráficas, desde el proceso de la pre prensa, pasando por la impresión y la aplicación de diversos acabados, es así como pueden observar cómo los temas revisados en el transcurrir de la clase se aplican en la realidad, partiendo de la premisa mencionada en líneas anteriores de procurar que los futuros diseñadores entiendan el funcionamiento y aplicación de los diferentes procesos más no convertirse en expertos técnicos en cada uno de los procesos. Estas actividades dependen mucho de la apertura y las facilidades de acercamiento que la industria pueda tener hacia la academia, para esto es muy importante la gestión que se hace por parte de diferentes docentes para lograr así obtener un acercamiento con las autoridades de las diferentes empresas y lograr la aceptación para ejecutar las mencionadas visitas, es necesario coordinar las fechas adecuadas para no alterar el normal funcionamiento de las plantas industriales, en especial porque existen ciertas temporadas en el año en la que dichas empresas tienen un alto flujo de trabajo y se les hace imposible recibir a grupos de estudiantes para que visiten sus instalaciones y procesos, este hecho se presenta principalmente porque la prioridad para la carrera es realizar visitas técnicas a empresas líderes en el mercado para que el aporte de estas en los estudiantes sea de relevancia.

La visualización de los diferentes tipos de impresión en visitas técnicas no solo se la realiza en empresas dedicadas a la producción de impresos, sino que también en otro tipo de organizaciones e instituciones en donde se ha realizado la implementación de piezas gráficas de diseño, de esta manera los estudiantes pueden tener una evidencia de que lo que se produce en una empresa de impresión se aplica, y debe ser aplicado, en otro ámbito para el que la pieza fue diseñada.

Es importante recalcar los diferentes aspectos que se evidencian en una visita técnica van relacionados directamente con los conceptos impartidos en clase, es así que desde la cátedra se propone realizar varias visitas y prácticas para que los estudiantes confronten los aspectos teóricos frente a la realidad de la industria.

Se han visitado estudios de diseño, como es el caso del estudio Ziette Diseño (Figura 2), quienes entre sus múltiples clientes tienen a su cargo el diseño de la revista que publica periódicamente un reconocido restaurante del Ecuador, en esta visita los estudiantes pudieron, además del diseño, conocer sobre los aspectos técnicos que siempre se deben tener en cuenta para la elaboración de artes finales, producción y edición fotográfica, plantear desde el inicio del proyecto los sustratos y acabados a utilizarse, de esta manera pueden observar a profesionales del diseño trabajando en la parte operativa del desarrollo de un proyecto. 


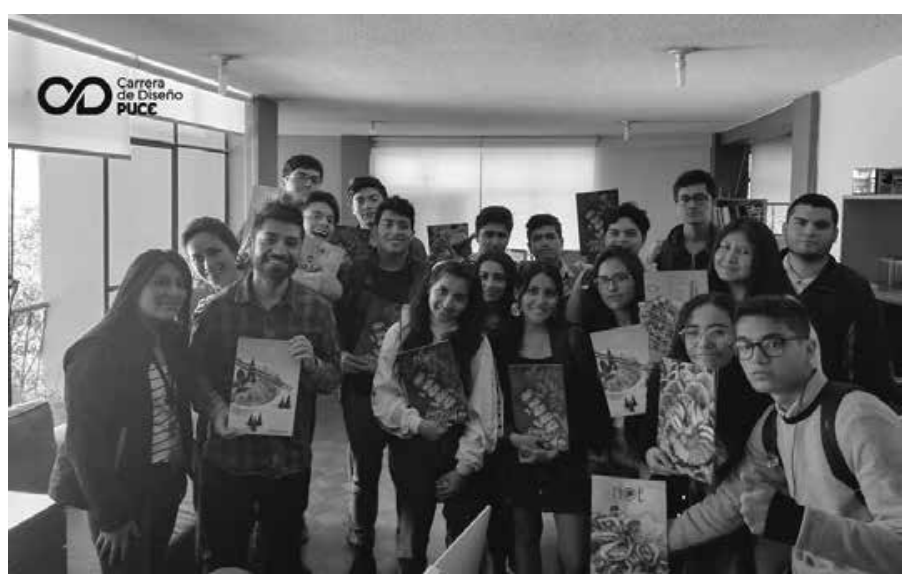

Figura 2. Alumnos de la Carrera de Diseño Gráfico durante su visita a estudio de diseño Ziette. Fuente: Carrera de Diseño de la PUCE.

Uno de los periódicos de mayor circulación en el país, diario El Comercio (Figura 3), también abrió sus puertas para visitar sus instalaciones, en sus instalaciones los estudiantes pueden constatar la inmediatez necesaria de la producción de una pieza impresa, dada su circulación diaria. Pudieron observar el armado de los artes, la elaboración de las placas térmicas y lo más importante, el proceso de impresión en rotativa y finalmente el proceso de corte, doblado y embalado del producto final para su distribución.

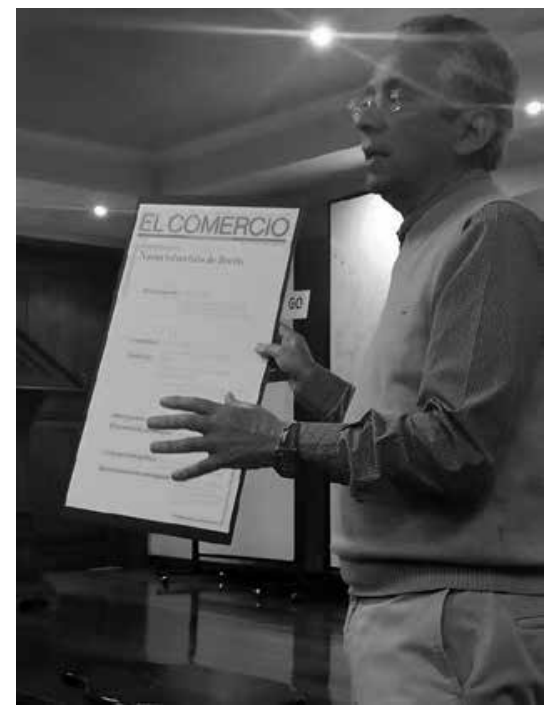

Figura 3. Visita a diario El Comercio. Fuente: Carrera de Diseño de la PUCE. 
Como se indicó en líneas anteriores, se propone visitar empresas líderes en el mercado nacional y, en algunos casos, a nivel regional, como es Imprenta Mariscal, que es una empresa que ha crecido gracias a la calidad de sus productos y se encuentra en una constante mejora de sus procesos de producción y siempre con tecnología de vanguardia, desde sus inicios se dedicó a la impresión offset y su principal actividad fue la producción de libros impresos, pero con el avance de la impresión digital desde hace algunos años decidió incursionar en el trabajo con tecnología HP Indigo, con lo que ha podido abarcar nuevos nichos de mercado, especialmente en el mundo del etiquetado, en donde se ha convertido en un fuerte competidor para empresas que proveen el servicio de flexografía.

En sus instalaciones se puede observar el proceso de pre prensa, cabe indicar que la empresa ha conformado un departamento de diseño para el desarrollo de plegadizas, otro nicho de mercado en el que ha incursionado con fuerza, gracias a las explicaciones de su personal los estudiantes comprenden la relación directa del diseño con la pieza gráfica y el mundo de la mercadotecnia. Lo más interesante de esta visita se desarrolla en la planta de producción, aquí los estudiantes pueden observar la diversidad de equipos con los que la imprenta trabaja, se verifica la elaboración de placas térmicas, se pueden observar trabajando a la máquinas offset de hasta 12 torres y rotativas, verificar el proceso de producción resulta sumamente interesante para los estudiantes, posteriormente se procede a visitar el área de los terminados gráficos, en donde la innovación de la empresa se hace evidente con diferentes tipos de acabados que resaltan la impresión y, como se ha dicho en líneas anteriores, otorgan un valor agregado al producto.

Una de las áreas que mayor impacto causan es la de impresión digital y los acabados gráficos que a estos impresos se aplican, los estudiantes comprenden, verificando físicamente, el porqué es necesaria la deformación de etiquetas para que se adapten a las diferentes formas de los envases, concepto revisado en el sistema de flexografía pero que también se aplica a la impresión digital, siendo de importancia el entendimiento de la configuración y preparado del arte final para que este proceso sea ejecutado eficientemente. Es necesario indicar que la imprenta ejecuta este proceso por medio de un software especializado pero que el diseñador debe conocerlo para tener presente esta particularidad en el momento de armar el arte. Finalmente la experiencia vivida por los diferentes grupos de estudiantes que han visitado a esta empresa ha sido siempre positiva, los futuros diseñadores comprenden la importancia del correcto armado técnico del arte y su relación directa con sus conocimientos de configuración de piezas gráficas comunicacionales.

Otro tipo de visita técnica que se propone realizar es la de los centros de reproducción de documentos elaborados en impresión digital, se han realizado dos tipos diferentes de visita, directamente con una de las marcas líderes del mercado, en alguna ocasión se tuvo la apertura para visitar las instalaciones de la marca Xerox en Quito, otra marca líder en el mercado, en donde se puede conocer el avance de la tecnología en prensas digitales, el funcionamiento de los equipos, la gestión de color desde el controlador del equipo y la calidad de impresión en los nuevos sustratos que la marca ha desarrollado. En esta visita la información se limita netamente al proceso de impresión, no es posible evidenciar la ejecución de acabados gráficos puesto que el giro de negocio de la empresa es la venta y distribución de equipos y sus respectivos suministros, pero es importante conocer la explicación técnica de sus expertos con relación a su tecnología. 
De otro lado, se tiene la posibilidad de acceder a diferentes centros de reproducción digital en donde sí es posible observar cada uno de los pasos para obtener un producto impreso de calidad, desde la preparación de artes para que queden listos para imprimir, tomando en cuenta el armado del arte para la aplicación de colores especiales en prensa digital, hasta la utilización de los diferentes acabados gráficos que pueden ser aplicados a productos impresos con los diferentes tipos de tecnología digital. En este tipo de centros no solo se puede conocer sobre impresión láser y prensa digital, sino que también se tiene un acercamiento a la impresión de gran formato e incluso a la tecnología de cama plana, la cual ha incursionado en los últimos años en el mercado ecuatoriano.

De la misma manera, se ha presentado la apertura de realizar visitas a centros de impresión por parte de otro tipo de distribuidores, relacionados con el diseño textil y la marca de impresoras EPSON, dicha marca ha desarrollado equipos para imprimir directamente en tela adicional a la línea de plotters y calandras para elaborar productos textiles sublimados. En estos centros se pueden observar cómo se debe tratar la tela previa y posteriormente a la impresión y cómo funciona exactamente el proceso de sublimación.

Visitar empresas u organizaciones donde se han implementado diferentes tipos de productos impresos en aplicaciones, como por ejemplo la señalética, brinda un acercamiento de los estudiantes con el mundo real y la visualización de productos elaborados por diseñadores cumpliendo la función para los que fueron creados, se ha tenido la apertura de empresas como Kruger, la cual posee unas instalaciones con diseño de señalética incorporado a su arquitectura y donde se puede apreciar claramente las diferentes técnicas utilizadas para la reproducción de sus productos gráficos y cómo son aplicados adecuadamente ; por otro lado, para lograr aplicar los conceptos impartidos en las diferentes cátedras es práctico el incluir a organizaciones reales en el proceso, para así empezar a vincular a los estudiantes en el ámbito laboral, que detecten los principales inconvenientes que se pueden presentar al trabajar para un comitente y puedan superarlos para así presentar sus propuestas tomando en cuenta sistemas de impresión y los materiales adecuados para la reproducción; generalmente son los museos o centros culturales en donde se tiene apertura para realizar este tipo de intervenciones, se parte de una visita para que los estudiantes constaten los diferentes tipos de requerimientos que la institución puedan tener y así ellos logren realizar sus propuestas tomando en cuenta los conceptos aprendidos en las aulas en las diferentes asignaturas que conforman el nivel.

Finalmente se tiene la oportunidad, cada dos años, de visitar la feria FIGRAMPA (Feria internacional de la industria gráfica, multimedios, publicitaria y afines) donde los estudiantes pueden observar en un solo lugar a una gran cantidad de expositores, mayoritariamente relacionados con el mundo de las artes gráficas, en la última feria llevada a cabo a principios del mes de noviembre del año 2019 las principales novedades que se presentaron estaban relacionadas con la impresión digital, específicamente con las prensas digitales, las marcas que desarrollan este tipo de equipos presentaron la ruptura de los formatos tradicionales de impresión, ahora es posible imprimir en tamaños que superan el metro de largo por los 33 centímetros de ancho, llamó mucho la atención la presentación de impresos con tóner de colores especiales como el blanco o colores fosforescentes, algo no existente hasta hace poco tiempo en nuestro medio y que ofrece nuevas oportunidades de elaboración de impresos novedosos a bajo tiraje y a costos convenientes. Marcas como RICOH y Konica Minolta 
también presentaron sus avances, con lo que los estudiantes pudieron constatar el avance parejo que han tenido todas las marcas que ofertan impresión digital y la versatilidad que esta presenta, teniendo así el acercamiento a las marcas y obteniendo muestras de impresión con lo que logran conformar un catálogo de productos impresos para que sea fácilmente identificable para ellos qué proceso de impresión es y qué marca lo ofrece.

Otro punto importante de recalcar para los estudiantes en la mencionada feria fue la presencia de materiales y sustratos para impresión, estuvieron presentes dos grandes distribuidores de papeles finos, tema que también fue revisado a inicios de la asignatura, los estudiantes pueden aumentar su catálogo de materiales y constatar la gran variedad de sustratos existentes para elaborar productos de alta calidad. Marcas líderes en el mercado mundial como Fedrigoni, Favini y Neenah Paper han incursionado en el Ecuador con una gran variedad de papeles finos a disposición de todos quienes estamos inmersos en la industria gráfica; es así como constatar por parte de los estudiantes la variedad de posibilidades que se tiene en relación a los sustratos existentes permite que abran sus mentes al momento de diseñar productos teniendo en cuenta el tipo de material que se va a utilizar. Este parte del trabajo de enseñanza del diseño adquiere importancia debido a que la enseñanza sale de las aulas y se les presenta a los estudiantes una visión real del mercado ecuatoriano y su relación con la profesión, a partir de estos acercamientos, tanto con la industria como con el potencial mercado, les plantea la posibilidad de confrontar dentro de sus trabajos académicos la teoría contra la posibilidad de tomar decisiones certeras y resolver problemas que se los presenta como proyectos (Frascara, 2017, p. 41 y p. 44), de esta manera el proceso de enseñanza resulta más efectivo, enfrentando inconvenientes, aprendiendo a resolverlos y presentando soluciones viables que concluyan en un buen producto de diseño.

\section{Dificultades encontradas}

Las principales dificultades encontradas en el proceso nacen de las costumbres de los estudiantes en no tener inmersa una cultura de lectura y la poca utilidad que obtienen del uso de las aulas virtuales, en ellas se muestran cada una de las tareas que se envían para ser ejecutadas, se indican todos los parámetros con los que cada trabajo será evaluado y se incluye una rúbrica de evaluación que indica la forma en que el arte debe ser enviado, planteando en cada componente el error con el que no se obtiene puntuación y el acierto; a pesar de presentar todos los datos para que los estudiantes no cometan errores y al no existir la mencionada cultura de lectura, los artes, en algunos casos, son enviados con errores, especialmente, y en concordancia con lo indicado anteriormente, los principales errores se encuentran en el envío equivocado del perfil de color de las imágenes y su resolución. Otro de los inconvenientes encontrados es la baja calidad de los servicios de impresión encontrados en los alrededores del campus universitario, en algunos casos los centros de reproducción están enfocados a brindar el servicio de fotocopiado y de impresión de trabajos y documentos en blanco y negro para otro tipo de carreras, y en otros casos el servicio de impresión digital a color y sus acabados se encuentran enfocados a la atención a otro tipo de clientes, por lo tanto a los estudiantes les cuesta conseguir impresiones de calidad, en 
muchos casos, y como ya se lo indicó, los equipos no reciben el mantenimiento adecuado, esto provoca que aparezcan en los impresos bandas no deseadas en los colores planos, por este motivo se incentiva a los estudiantes a buscar otro tipo de proveedores, en Quito, y a pocas cuadras de la universidad se encuentra el barrio que fue la cuna de las artes gráficas en la ciudad en el año 1974 (www.elcomercio.com), el barrio América, en donde se encuentra una gran cantidad de proveedores de todo tipo y relacionados con el mundo de la impresión, en este barrio se evidencia la afirmación realizada en líneas anteriores sobre el avance de la impresión digital, existen varios negocios que brindan servicios de impresión digital láser e incluso HP Indigo, en donde los estudiantes pueden elaborar sus trabajos y con mejor calidad que los impresos que se pueden obtener cercanos a la PUCE.

$\mathrm{Al}$ elaborar la base de datos de proveedores de servicios se presenta otro inconveniente, lastimosamente las personas que trabajan brindando este tipo de servicios no tiene una cultura de servicio al cliente y al ver a jóvenes estudiantes no les prestan la atención debida y en muchos casos no les gusta brindar la información requerida, más allá de indicarles que es para una base de datos que será repartida entre varios profesionales y futuros diseñadores gráficos, el lidiar con este tipo de proveedores es una complicación, pero que se vuelve necesaria para capacitar a los estudiantes con el manejo de gente difícil en el mundo real.

En cuanto a las visitas técnicas, la principal complicación, y como se lo había indicado, consiste en coordinar los tiempos de las empresas para no entorpecer sus flujos de trabajo y poder visitarlos en momentos en que no se encuentren en sus picos altos de producción, teniendo en cuenta también los tiempos de la planificación académica de la carrera.

Este tipo de inconvenientes deben ser aprovechados para construir aprendizaje, los estudiantes en poco tiempo, ya como profesionales, deberán enfrentar mayores complicaciones en sus labores y deben prepararse para estas desde la academia.

\section{Conclusión}

La enseñanza del diseño no puede dejar de lado a la tecnología y a las disciplinas colaterales relacionadas con ella, los procesos de impresión son un complemento que deben ser conocidos por los diseñadores para finalizar la configuración de piezas comunicacionales, es necesario entonces, manejar la información que se encuantra alrededor de la impresión para cumplir con los objetivos que cada proyecto de diseño plantee.

El tener siempre presente la correcta configuración técnica de artes finales u originales producirá un correcto flujo de trabajo, evitando problemas, tanto para el diseñador como para el impresor, que posteriormente provoquen pérdidas de tiempo y dinero.

Finalmente, el acercamiento de la academia con la industria es un punto sumamente importante en el desarrollo de las dos áreas, la academia se alimenta de la experiencia de la industria y ésta de estudiantes de diseño gráfico que puedan realizar sus prácticas pre profesionales en sus instalaciones y de potenciales clientes que ya en el ámbito laboral puedan hacer uso de sus servicios. Esta relación debe ser alimentada constantemente para beneficio de las dos partes. 


\section{Referencias}

Adobe.com. Adobe PostScript. Recuperado el 4 de noviembre de 2019 de: https://www. adobe.com/la/products/postscript.html

Bienal Iberoamericana de Diseño. 50 Talentos. Ideas para un mundo mejor. Recuperado el 21 de diciembre de 2019 de: http://bid-dimad.org/octavoencuentro/wp-content/ uploads/2019/10/50T_seleccionados_listado-1.pdf?fbclid=IwAR1xUxdqe7aJGMUIM s2Ghd35J82nAFAkyvaCuEKuGGGOZ_3yPjaR4dM0psw

Capuz Rizo, S., Gómez, T. (2002). Ecodiseño, Ingeniería del ciclo de vida para el desarrollo de productos sostenibles. Valencia. España. Editorial de la UPV.

Cuatrecasas, L. (2012). Organización de la producción y dirección de operaciones. Sistemas actuales de gestión eficiente y competitiva. Madrid. España. Ediciones Diezsantos.

Carrera de Diseño Gráfico PUCE. Recuperado el 3 de noviembre de 2019 de: https://www. puce.edu.ec/portal/carreras/diseno-grafico/?tab=tab-curriculum

Carrera de Diseño Gráfico PUCE. Documento de Rediseño de la Carrera de Diseño Gráfico PUCE. Recuperado el 21 de diciembre de 2019 de: https://puceeduec-my.sharepoint. com/:b:/g/personal/mlozada685_puce_edu_ec/EcfatHOWWEBPpCEVm9ud1LQBYq1_eYFQjD6Se2dQfewdKQ?e=Fuf6mI

Diario El Comercio. El barrio América es otro nexo del Quito antiguo y el moderno. Recuperado el 1 de diciembre de 2019 de: https://www.elcomercio.com/actualidad/quitobarrios-historia-modernidad.html

Escribano, A. Del Valle, A. (Coords.). (2010). El aprendizaje basado en problemas (ABP). Madrid. España. Narcea S.A. Ediciones.

FIGRAMPA. Feria internacional de la industria gráfica, multimedios, publicitaria y afines. Recuperado el 17 de noviembre 2019 de: https://figrampa.com.ec/

Frascara, J. (2017). Enseñando diseño. Buenos Aires. Argentina. Infinito

Gatter, M. (2010). Manual de impresión para diseñadores gráficos. Barcelona. España. Parramón Diseño.

Gráffica.info (2019). ¿Cómo debe ser la formación en diseño hoy para preparar al diseñador del mañana? Recuperado 17 de noviembre de 2019 de: https://graffica.info/como-debeser-la-formacion-en-diseno-hoy-para-preparar-al-disenador-del-manana/?fbclid=IwA R0vDV7tY7JnpwClyroT44evwYdR4_iptCcQu-tZJolfYuEgPAWbwUXbm94

Huella de carbono en productos papeleros. Recuperado el 10 de diciembre de: https://www. afco.es/co2

Huella ecológica. Recuperado el 10 de diciembre de: http://www.clusterpapel.com/upload/ zona\%20de\%20prensa/np\%20huella\%20de\%20carbono.pdf

Mazzeo, C. (2017) Diseño y sistema. Bajo la punta del iceberg. Ciudad Autónoma de Buenos Aires: Infinito

PUCE, Repositorio de Tesis de Grado y Posgrado. Recuperado el 17 de noviembre 2019 de: http://repositorio.puce.edu.ec/handle/22000/17020

Tobón Tobón, S. (2010) Formación integral y competencias. Pensamiento complejo, currículo, didáctica y evaluación. Bogotá: Ecoe Ediciones.

Vargas Morandi, L. (2014). Manual técnico de Sistemas de Reproducción. Alajuela. Universidad de Costa Rica.

Yeang, K. EcoDesign, A Manual for Ecological Design, Wiley Academy, 2006. 


\begin{abstract}
Within the teaching of design it is necessary to understand that the configuration of a product includes the conceptualization and the relationship of each of the steps that must be followed to get a printed product, this leads us to take into account from the beginning of the process to the appropriate selection of the printing and post press system, which must be in accordance with the initial concept of the communicational product. Additionally, the current requirements related to environmental standards acquire main interest in the configuration of graphic products, for this it is essential that from the academy the new designers are trained with all the tools so that they are able to face the new challenges that the profession presents in the relation Graphic Design -printed product- environment, taking into account that both the printing system and the finishes used must be selected from the beginning of the process as part of the concept that you wish to communicate.
\end{abstract}

Keywords: Graphic design - printing processes - finishes - teaching - environment - innovation

Resumo: No ensino do design, é necessário entender que a configuração de um produto inclui a conceituação e o relacionamento de cada uma das etapas a serem seguidas para obter um produto impresso, o que nos leva a considerar desde o início do processo para a seleção adequada do sistema de impressão e pós-impressão, que deve estar de acordo com o conceito inicial do produto de comunicação. Além disso, os requisitos atuais relacionados às normas ambientais adquirem maior interesse na configuração de produtos gráficos, para isso é essencial que a academia treine novos designers com todas as ferramentas para que possam enfrentar os novos desafios que a profissão apresenta no relacionamento Design gráfico -produto impresso- ambiente, levando em consideração que o sistema de impressão e os acabamentos utilizados devem ser selecionados desde o início do processo como parte do conceito a ser comunicado.

Palavras chave: Design gráfico - processos de impressão - acabamentos - ensino - meio ambiente - inovação

[Las traducciones de los abstracts fueron supervisadas por el autor de cada artículo] 